\title{
Pathological validation of auscultation of the elderly heart
}

\author{
M. J. Denham \\ M.D., M.R.C.P.
}

\author{
Ariela Pomerance \\ M.D., M.R.C.Path.
}

\author{
H. M. HodKINSON \\ D.M., F.R.C.P. \\ Northwick Park Hospital, Watford Road, Harrow, Middlesex
}

\begin{abstract}
Summary
Systolic murmurs present in 129 geriatric patients followed to post-mortem were assessed as mitral or aortic in origin by simple clinical assessment alone. Post-mortem examination contradicted clinical findings in only $2 \%$ of cases. Mitral valve pathology, mostly post-inflammatory scarring or mucoid degeneration, was present in $50 \%$ of the cases with murmurs. There was a significant correlation between the presence of murmurs, particularly mitral murmurs, and congestive cardiac failure, and there was also a significant correlation with age. A tendency for aortic systolic murmurs to be associated with a higher mean systolic blood pressure was not significant and there was no significant association between systolic murmurs and ischaemic heart disease.
\end{abstract}

\section{Introduction}

Assessment of cardiac murmurs is one of the most common clinical problems in geriatric practice. Most clinical studies consider systolic murmurs to be mainly of aortic origin (Bruns and Van der Hauwaert, 1958; Bethel and Crow, 1963; Davison and Friedman, 1968; Griffiths and Sheldon, 1975), while those including post-mortem observations indicate that the majority are mitral (Pomerance, 1965; Howell, 1970). Clinical differentiation of aortic and mitral murmurs, although difficult (Burch and Phillips, 1963), is regarded as of practical importance as mitral murmurs have been considered relevant to the development of congestive cardiac failure (Pomerance, 1965; Griffiths and Sheldon, 1975). Difficulties in assessing the heart of an elderly person may be due to chest deformities, emphysema, expiratory rales or the patient's inability to co-operate. As part of a large series of clinical pathological studies of geriatric cardiology, a prospective study was made comparing clinical assessment with post-mortem and phonocardiographic findings.

\section{Patients and methods}

The patients studied had all been admitted to the Geriatric Unit at Northwick Park Hospital. A high proportion of those assessed were acutely ill. The patients were examined within $24 \mathrm{hr}$ of admission. Clinical assessment and diagnosis of the cardiovascular system was made by one of the authors (M.J.D.) using conventional clinical criteria (Wood, 1968). Electrocardiography and, when practical, phonocardiography, were performed within the first few days in hospital, but always after clinical assessment. Post-mortems were requested for all patients who died, consent being obtained in about twothirds of cases. The hearts were examined by a pathologist (A.P.) with a particular interest in cardiac pathology.

\section{Results}

Cardiac murmurs were heard in 129 of 313 patients (130 male, 183 female) who came to post-mortem. The clinical designation of the murmurs is shown in Table 1. Owing to omissions at the time of examination, thirteen of the 313 patients were not classified with regard to their murmurs.

There was no significant difference in the distribution of murmurs between the sexes, although both mitral and aortic type murmurs occurred more frequently in females.

Pathology of the valvular apparatus was found in 115 patients, as shown in Table 2 .

Pure mitral valve apparatus abnormalities accounted for $52 \%$ of the total. The commonest pure mitral lesion was post-inflammatory scarring, which varied from a relatively minor degree of puckering

TABLE 1. Clinical classification of the murmurs

\begin{tabular}{lc}
\hline Clinical classification of murmurs & $\begin{array}{c}\text { Number of } \\
\text { patients }\end{array}$ \\
\hline Mitral type only & 60 \\
Aortic type only & 34 \\
Combined mitral and aortic type & 21 \\
Atrial septal defect (ASD) & 1 \\
Unclassified & 13 \\
& $-\frac{129}{2}$ \\
\hline
\end{tabular}


TABLE 2. Cardiac pathology found at post-mortem

\begin{tabular}{llr}
\hline & \multicolumn{1}{c}{ Type of pathology } & Number \\
\hline & Post-inflammatory & 22 \\
Ballooning (mucoid degeneration) & 16 \\
Ming calcification & 6 \\
Ritral valve pathology only (60) & Marked notularity & 2 \\
Mapillary muscle fibrosis & 1 \\
with normal valve & 13 \\
Aortic valve pathology only & Calcification & 24 \\
$\begin{array}{l}\text { Combined mitral and aortic } \\
\text { valve pathology }\end{array}$ & Calcification in both valves & 28 \\
Others & ASD & 2 \\
& Tricuspid incompetence & 1 \\
\hline
\end{tabular}

TABLE 3. Correlation between clinical assessment and post-mortem findings

\begin{tabular}{|c|c|c|c|c|c|c|}
\hline \multirow[b]{2}{*}{$\begin{array}{l}\text { Clinical designation } \\
\text { and total }\end{array}$} & \multicolumn{6}{|c|}{ Pathology } \\
\hline & Nil & $\begin{array}{c}\text { Mitral } \\
\text { pathology } \\
\text { only }\end{array}$ & $\begin{array}{l}\text { Aortic } \\
\text { pathology } \\
\text { only }\end{array}$ & $\begin{array}{l}\text { Combined mitral } \\
\text { and aortic } \\
\text { pathology }\end{array}$ & ASD & Other \\
\hline No murmurs (184) & 166 & 15 & 3 & 0 & 0 & 0 \\
\hline Mitral murmurs (60) & 2 & $\underline{55}$ & 3 & 0 & 0 & 0 \\
\hline Aortic murmurs (34) & 8 & 3 & $\underline{22}$ & 0 & 0 & 1 \\
\hline $\begin{array}{l}\text { Combined mitral and } \\
\text { aortic murmurs ( } 21)\end{array}$ & 0 & 4 & 3 & 14 & 0 & 0 \\
\hline ASD (1) & 0 & 0 & 0 & 0 & 1 & $\mathbf{0}$ \\
\hline
\end{tabular}

and distortion to well marked changes of classical rheumatic type. There was a highly significant tendency for degenerative calcification to affect both valves simultaneously $(P<0.0005)$.

There was a good correlation between clinical assessment and post-mortem findings, as shown in Table 3, which excludes the thirteen unclassified patients.

There is total agreement between clinical diagnosis and post-mortem findings in $257(82 \%)$ of the patients. In seven $(2 \%)$ patients the clinical diagnosis was incorrect and in eighteen $(6 \%)$ no murmurs were heard, mainly because of respiratory added sounds. Murmurs were heard in ten $(3 \%$ ) patients in whom there was no relevant cardiac pathology at postmortem; five of these patients were anaemic, one had pulmonary thrombosis, one was hypertensive, while no explanation was found in the remaining three.
Phonocardiograms were available in a minority of cases coming to post-mortem. A detailed analysis is to be published elsewhere, but in essence phonocardiography showed no clear advantage over basic, simple clinical observations by one observer.

There was a good correlation between age and the presence of murmurs, particularly mitral, as shown in Table 4.

There was no correlation between the presence of murmurs and mean diastolic blood pressure, although there was a non-significant trend for aortic murmurs to be associated with a slightly higher mean systolic blood pressure. There was a significant positive correlation between the presence of congestive cardiac failure and the presence of cardiac murmurs in general $(P<0.01)$. This was particularly marked with mitral murmurs $(P<0.005)$. There was no significant correlation of congestive

TABLE 4. The correlation between age and the presence of murmurs

\begin{tabular}{lccc}
\hline & $\begin{array}{c}\text { Mean age } \\
\text { (years) }\end{array}$ & $\begin{array}{c}\text { Standard } \\
\text { deviation }\end{array}$ & $\begin{array}{c}P \text { (for difference in } \\
\text { patients without murmurs) }\end{array}$ \\
\hline Patients without murmurs & $78 \cdot 7$ & $7 \cdot 8$ & - \\
Patients with mitral murmurs & $82 \cdot 4$ & $6 \cdot 4$ & $<0.005$ \\
Patients with aortic murmurs & $79 \cdot 6$ & $9 \cdot 5$ & N.S. \\
Patients with other murmurs & $81 \cdot 3$ & $6 \cdot 4$ & $<0.05$ \\
All patients with murmurs & $81 \cdot 3$ & $7 \cdot 3$ & $<0.01$ \\
\hline
\end{tabular}


cardiac failure with the presence of aortic murmurs. There was no correlation between the presence of murmurs and the findings of ischaemic heart disease at post-mortem, although papillary muscle fibrosis appeared to be responsible for mitral murmurs in thirteen cases.

\section{Discussion}

The two main points which emerge from this investigation are that the source of systolic murmurs can be correctly identified in almost all cases by simple clinical assessment alone and that the majority of murmurs are associated with mitral pathology. Murmurs may be difficult to hear owing to mechanical difficulties. In this series eighteen patients had valvular pathology, but no murmurs were heard. Eight of these patients had loud respiratory added sounds making auscultation of the heart unreliable and five were in congestive cardiac failure at the time of the examination. Murmurs may be heard in the absence of valvular pathology in conditions such as severe anaemia or thyrotoxicosis. In this study murmurs were heard in ten patients without valvular pathology, which could be explained by such mechanisms in five instances.

The present findings that the abnormalities of the mitral valve apparatus are more common than aortic abnormalities confirm the retrospective clinicopathological study of Pomerance (1968), and the smaller series followed to post-mortem by Howell (1970), but are at variance with those of essentially clinical studies (Bruns and Van der Hauwaert, 1958; Bethel and Crow, 1963; Davison and Friedman, 1968; Griffiths and Sheldon, 1975). This discrepancy may be due to the small number of patients followed to post-mortem in the latter papers and differences in the types of patients under consideration. Bethel and Crow (1963) and Davison and Friedman (1968) carried out studies which were purely clinical with no pathological data. Autopsies had been carried out in only twenty-three out of the 146 cases in Bruns and Van der Hauwaert's study (1958). The number of post-mortems in Griffiths and Sheldon's study (1975) was also small, and in Stirpe and Scoppola's entirely retrospective study (1968) the findings correlated poorly with clinical diagnosis. However, the present results agree with those of Bruns and Van der Hauwaert (1958) and Griffiths and Sheldon (1975) that the incidence of murmurs increases with age.

Aortic murmurs have been generally regarded as less clinically significant than mitral murmurs. In contrast to the previous clinical studies, the patients in this study were all acutely ill when examined and subsequently died. Thus a higher proportion of mitral valvular pathology may be reasonably expected. The better prognosis of aortic murmurs was confirmed by the finding of a significant correlation with congestive cardiac failure in mitral murmurs, while there was no significant correlation in the case of aortic murmurs.

A high proportion of patients with mitral murmurs had ring calcification and/or mucoid degeneration of the cusps. These lesions are a potential site for infective endocarditis or spontaneous rupture of the chordae with further cardiac decompensation (Read, Thal \& Wendt, 1965), and the correct identification of mitral murmurs is, therefore, important.

Ischaemia may cause disordered function of the sub-valvular apparatus and consequent mitral incompetence (Goodwin, 1968). Although ischaemic papillary muscle fibrosis appeared to be the only explanation for systolic murmurs in thirteen patients, there was no significant correlation between the murmurs and ischaemic heart disease in general.

\section{References}

Bethel, C.S. \& Crow, E.W. (1963) Heart sounds in the aged. American Journal of Cardiology, 11, 763.

BRUNS, D.I. \& VAN DER HAUWAERT, L.C. (1958) The aortic systolic murmur developing with increasing age. British Heart Journal, 20, 370.

BurCh, G.E. \& Phillips, J.H. (1963) The murmur of aortic stenosis and mitral insufficiency masquerading as one another. American Heart Journal, 66, 439.

Davison, E.T. \& Friedman, S.A. (1968) Significance of systolic murmurs in the aged. New England Journal of Medicine, 279, 225.

GoodwIN, J.F. (1968) Mitral regurgitation in congestive cardiomyopathy. Postgraduate Medical Journal, 44, 62.

Griffiths, R.A. \& SHELDON, M.G. (1975) The clinical significance of systolic murmurs in the elderly. Age and Ageing, $4,99$.

Howell, T.H. (1970) Systolic murmurs in aged patients. Gerontologia clinica, 12, 275.

Pomerance, A. (1965) Pathology of the heart with and without heart failure in the elderly. British Heart Journal, 27, 697.

Pomerance, A. (1968) Cardiac pathology and systolic murmurs in the elderly. British Heart Journal, 30, 687.

Read, R.C., Thal, A.P. \& Wendt, V.E. (1965) Symptomatic valvular myxomatous transformation. Circulation, 32, 897.

StIRPE, G. \& Scoppola, L. (1968) Frequenza e significato dei soffi valvolari nell'età senile. Giornale di gerontologia, 16, 1003.

Wood, P. (1968) Diseases of the Heart and Circulation, 3rd Edn. Eyre and Spottiswoode, London. 